\title{
Teori Evolusionisme
}

\author{
Nama: Tedy Fermansyah
}

Bp: 2010003600147

Email: tedyfermansyah123@gmail.com

\section{FAKULTAS HUKUM UNIVERSITAS EKASAKTI}

\author{
2021
}

\section{A. PENDAHULUAN}

Antropologi secara etimologis berasal dari bahasa Yunani. Kata Anthropos berarti mansia dan logos berarti ilmu pengetahuan. Jadi, antropologi adalah ilmu yang mempelajari manusia. Oleh karena itu antropologi didasarkan pada kemajuan yang telah dicapai ilmu pengetahuan sebelumnya.

Pitirim Sorokim mengatakan bahwa Sosiologi adalah suatu ilmu yang mempelajari hubungan dan pengaruh timbal balik antara aneka macam gejala- gejala sosial (gejala ekonomi dengan agama, keluarga dengan moral, hukum dengan ekonomi) dengan gejala lainnya (nonsosial).

Berbeda dengan pendapat Rouceke dan Warren yang mengatakan bahwa Sosiologi adalah ilmu yang mempelajari hubungan manusia dengan kelompokkelompok.

Berasarkan uraian di atas, maka Sosiologi adalah jelas merupakan ilmu sosial yang objeknya adalah masyarakat sebagai ilmu. Ia berdiri sendiri karena telah memiliki unsur ilmu pengetahuan.

Dalam ilmu antropologi hukum dipelajari juga mengenai Status atau kedudukan, Nilai, Norma dan juga Budaya atau kebudayaan. Keempat hal tersebut berkaitan erat dengan ilmu antropologi hukum.

\section{B. PEMBAHASAN}

Atropologi Berasal dari bahasa Yunani, Antropos berarti manusia dan logos berarti ilmu atau studi tentang sesuatu. Para antropolog mengemukakan antropologi sebagai studi tentang umat manusia yang berusaha menyusun generalisasi yang bermanfaat tentang manusia dan perilakunya, dan untuk memperoleh pengertian 
ataupun pemahaman yang lengkap tentang keanekaragaman manusia.

Koentjoroningrat (2009) mendefinisikan antropologi sebagai ilmu tentang manusia dan merupakan suatu istilah yang sangat tua. Pada masa lalu istilah antropologi digunakan dalam arti lain yaitu ilmu tentang ciri-ciri tubuh manusia. Bahkan disebut sebagai ilmu anatomi. Dalam perkembangan fase ketiga sejarah perkembangan antropologi, istilah antropologi dipakai terutama di Inggris dan Amerika dalam arti yang sama dengan etnologi pada awalnya. Di Amerika istilah antropologi dipakai dalam arti yang luas, meliputi bagian-bagian fisik maupun sosial dari imu tentang manusia. Di Eropa Barat dan Tengah, istilah antropologi dipakai dalam arti khusus yaitu ilmu tentang ras-ras manusia dipandang dari ciri- ciri fisiknya.

Muncul pertengahan abad 19 sebagai disiplin ilmu sendiri dg tokohnya Edward Burnett Taylor (1832-1917) penulis Primitive Culture \& penemu teori Animisme yg menjadi awal teori Agama, James George Frazer (1854-1941) melahirkan teori Magi melalui The Golden Bough, RR. Marett penemu teori Dinamisme, dan Andrew Lang penemu teori Dewa Tertinggi. Angkatan tertua ini berasumsi bahwa budaya adalah hasil cipta, rasa dan karsa manusia, ia mengalami perubahan secara evolusioner. Selanjutnya adalah Claude Levi-Strauss pencetus Antropologi Struktural dengan strukturalisme sbg perspektifnya. Lahir pula Antropologi Kognitif, dikembangkan Ward H. Goodenough (1950-an). Aliranin imembawa definisi budaya dari yg fisik menuju pengertian bahwa budaya sbg sistem pengetahuan. Aliran Antropologi Simbolik-Interpretatif yg dipandegani Clifford Geertz yang melihat sistem simbol sbg media pemahaman manusia atas sistem nilai dan sistem koginitifnya.

Paham yang menyatakan bahwa prinsip dasar proses alam adalah perubahan dan perkembangan bentuk yang lebih rendah dan seder hana menuju bentuk yang lebih tinggi dan mendekati kesempurnaan. Dalam pandangan ini, alam semesta dan kehidupan manusia dalam segala perwujudan dan aspeknya merupakan hasil perkembangan dan masih berkembang terus. Maka, evolusionisme memasuki berbagai bidang ilmu dan filsafat, seperti biologi, antropologi, psikologi, kosmologi, budaya, metafisi ka, etika, dan agama.

Evolusionisme mempunyai banyak bentuk, tergan tung pada penerapan dan pengandaian dasarnya. Ma ka ada berbagai evolusionisme, yaitu evolusionisme mekanistik, naturalistik, vitalistik atau organismik, idealistik, pragmatik. Evolusionisme juga bersifat ateistik, panteistik maupun teistik, tergantung pada . penempatan Pencipta dalam proses evolusi yang ber sangkutan.

Sering kali evolusionisme dianggap hasil pemikiran modern, padahal dalam kenyataannya, evolusionisme .. berakar jauh di masa lampau, yaitu pada pemikiran 
Yunani. Anaximander (611-546 SM) mengembangkan suatu pandangan lengkap tentang evolusi kosmos yang berasal dari apeiron yang juga menjadi tujuan kem bali segala hal, termasuk manusia. Herakleitos (533- - 475 SM) mengajarkan bahwa segala sesuatu mengalir dan tak satu hal pun bisa menghalangi proses itu. Wa lau ada logos rasional yang menjaga tertib segala se suatu, prinsip utama realitas adalah perubahan. Pan dangan evolusionistis juga dijumpai pada pemikiran Empedokles, Anaxagoras, Demokritus, Leucippus, Epikurus, dan beberapa filsuf lainnya. Aristoteles juga mengembangkan pandangan evolusi.

a) Asumsi Dasar

Kebudayaan mengalami proses perubahan dari satu tahap ketahap selanjutny secara evolutif

Tokoh:

a. E.B. Taylor : menemukan teori animisme.

b. J.J. Bachofen : menemukan teori pembentukan keluarga

c. J.G. Frazer : menemukan teori batas akal atau magi

d. R.R. Maret : menemukan teori dinamisme

e. Andrew Lang : menemukan teori dewa tertinggi

b) Kebudayaan dlm Perspektif Evolusionisme

Kebudayaan dalam perspektif Antropologi Evolusionisme terbagi dalam tiga konsepsi :

1) Kebudayaansebagaisebuahsistem(culturalsystem)

Yaitu berupa gagasan, pikiran, konsep , nilai, norma, pandangan, undang-undang.

Kesemuanya dimiliki oleh pemangku

ide dan bersifat abstrak.

2) Kebudayaansebagaisistemsosial

Menurut C. Kluckholn kebudayaan sebagai sistem sosial terdiri dari :

1) Sistemperalatandanperlengkapanhidup 2) Sistemmatapencarian

3) Sistemkemasyarakatan

4) Bahasa

5) Kesenian

6) Sistempengetahuan

c)

7) Sistemreligi

Ketujuh isi kebudayaan itu disebut juga sebagai Unsur-unsur Kebudayaan atau

Culturan Universal Kebudayaan sebagai hasil tingkah laku manusia (material culture)

Terbagi menjadi 2

1. Benda (Artifak) atau Material Culture

2. Tingkah laku manusia itu sendiri

Cara pandangEvolusionisme 
Mendeskripsikan unsur-unsur budaya universal dan pola perubahan yg teramati melalui mekanisme pembandingan kebudayaan yg hidup dan berkembang dalam sebuah entitas budaya

d) MetodeKomparasi

Metode Komparatif-Diakronik \& Metode Komparatif- Sinkronik $\rightarrow$ PERUBAHAN KEBUDAYAAN

e) Metode Komparatif-SinkroniL

Peneliti meneliti dua entitas budaya yang berbeda dari satu komuniti yang sama dlm waktu bersamaan.

Contoh: Penelitian E.M Burner th 1958 thd kebudayaan Batak Toba pd masy desa \& kota Medan. Hasilnya masyarakat desa \& kota sama2 kuat memegang tradisi Batak ketika berhadapan dg budaya lain dikota.

f) Metode Komparatif-Diakronik

Peneliti meneliti suatu kebudayaan dari entitas masyarakat tertentu pada satu waktu lalu dikaji lagi pada beberapa saat kemudian pada entitas yang sama.

Contoh Penelitian R. Firth pada Komunitas pulau Tikopea Polinesia pada tahun 1929, lalu dilakukan Lagi 25 th kemudian. Hasilnya ada perubahan signifikan dari kebudayaan tradisional ke kebudayaan modern.

\section{PENUTUP}

Antropologi adalah ilmu yang mempelajari manusia. Oleh karena itu antropologi didasarkan pada kemajuan yang telah dicapai ilmu pengetahuan sebelumnya.

Pengertian Antropologi dapat dilihat dari 2 sisi yaitu Antropologi sebagai ilmu pengetahuan artinya bahwa Antropologi merupakan kumpulan pengetahuan-pengetahuan tentang kajian masyarakat dan kebudayaan yang disusun secara sistematis atas dasar pemikiran yang logis. Dan pengertian Antropologi yang kedua adalah cara-cara berpikir untuk mengungkapkan realitassosial dan budaya yang ada dalam masyarakat dengan prosedur dan teori yang dapat dipertanggungjawabkan kebenarannya secara ilmiah.

Setelah di kaji kita dapat mengemukakan hasilnya bahwa manfaat di dalam antropologi hukum sangat luas.Antropologi hukum telah memberikan kontribusi yang sangat besar bangi perkembangan ilmu hukum.Dan kesimpulan yang dapat diambil adalah dimana pun kita ,kita tidak akan pernah jauh dari hukum selama kita berada di Negara hukum.

\section{DAFTAR PUSTAKA}

Darmini Roza dan Laurensius Arliman S Peran Pemerintah Daerah Di Dalam Melindungi Hak Anak Di Indonesia, Masalah-Masalah Hukum, Volume 47, Nomor 1, 2018. 
Laurensius Arliman S, Komnas HAM dan Perlindungan Anak Pelaku Tindak Pidana, Deepublish, Yogyakarta, 2015.

Laurensius Arliman S, Penguatan Perlindungan Anak Dari Tindakan Human

Trafficking Di Daerah Perbatasan Indonesia, Jurnal Selat, Volume 4, Nomor 1, 2016.

Laurensius Arliman S, Problematika Dan Solusi Pemenuhan Perlindungan Hak Anak Sebagai Tersangka Tindak Pidana Di Satlantas Polresta Pariaman, Justicia Islamica, Volume 13, Nomor 2, 2016.

Laurensius Arliman S, Pelaksanaan Perlindungan Anak Yang Tereksploitasi Secara Ekonomi Oleh Pemerintah Kota Padang, Veritas et Justitia, Volume 2, Nomor 1, 2016. Laurensius Arliman S, Kedudukan Ketetapan MPR Dalam Hierarki Peraturan Perundang-Undangan Di Indonesia,Lex Jurnalica, Volume 13, Nomor 3, 2016. Laurensius Arliman S, Komnas Perempuan Sebagai State Auxialiary Bodies Dalam Penegakan Ham Perempuan Indonesia, Justicia Islamica, Volume 14, Nomor 2, 2017. Laurensius Arliman S, Peranan Pers Untuk Mewujudkan Perlindungan Anak Berkelanjutan Di Indonesia, Jurnal Ilmu Hukum Tambun Bungai, Volume 2, Nomor 2, 2017.

Laurensius Arliman S, Mewujudkan Penegakan Hukum Yang Baik Untuk Mewujudkan Indonesia Sebagai Negara Hukum, Jurnal Hukum Doctrinal, Volume 2, Nomor 2, 2017.

Laurensius Arliman S, Participation Non-Governmental Organization In Protecting Child Rights In The Area Of Social Conflict, The 1st Ushuluddin and Islamic Thought International Conference (Usicon), Volume 1, 2017.

Laurensius Arliman S, Partisipasi Masyarakat Dalam Pembentukan Perundang Undangan Untuk Mewujudkan Negara Kesejahteraan Indonesia, Jurnal Politik Pemerintahan Dharma Praja, Volume 10, Nomor 1, 2017, https://doi.org/10.33701/jppdp.v10i1.379.

Laurensius Arliman S, Peran Komisi Perlindungan Anak Indonesia Untuk

Mewujudkan Perlindungan Anak, Jurnal Respublica Volume 17, Nomor 2, 2018. Laurensius Arliman S, Menjerat Pelaku Penyuruh Pengrusakan Barang Milik Orang Lain Dengan Mempertimbangkan Asas Fungsi Sosial, Jurnal Gagasan Hukum, Volume 1,Nomor 1, 2019.

Laurensius Arliman S, Ilmu Perundang-Undangan Yang Baik Untuk Negara Indonesia, Deepublish, Yogyakarta, 2019.

Laurensius Arliman S, Isdal Veri, Gustiwarni, Elfitrayenti, AdeSakurawati, Yasri, Pengaruh Karakteristik Individu, Perlindungan Hak Perempuan Terhadap Kualitas Pelayanan Komnas Perempuan Dengan Kompetensi Sumber Daya Manusia Sebagai Variabel Mediasi, Jurnal Menara Ekonomi: Penelitian dan Kajian Ilmiah Bidang Ekonomi, Volume 6, Nomor 2, 2020.

Laurensius Arliman S, Pendidikan Kewarganegaraan, Deepublish, Yogyakarta, 2020.

Laurensius Arliman S, Makna Keuangan Negara Dalam Pasal Pasal 23 E Undang-Undang Dasar 1945, Jurnal Lex Librum, Volume 6, Nomor 2 Juni 2020, http://dx.doi.org/10.46839/1ljih.v6i2.151. 
Laurensius Arliman S, Kedudukan Lembaga Negara Independen Di Indonesia Untuk Mencapai Tujuan Negara Hukum, Kertha Semaya Journal Ilmu Hukum, Volume 8, Nomor 7, 2020.

Laurensius Arliman S, Pelaksanaan Assesment Oleh Polres Kepulauan Mentawai Sebagai Bentuk Pelaksanaan Rehabilitasi Bagi Pecandu Dan Korban Penyalahgunaan Narkotika, Jurnal Muhakkamah, Volume 5, Nomor 1, 2020.

Laurensius Arliman S, Aswandi Aswandi, Firgi Nurdiansyah, Laxmy Defilah, Nova Sari Yudistia, Ni Putu Eka, Viona Putri, Zakia Zakia, Ernita Arief, Prinsip,

Mekanisme Dan Bentuk Pelayanan Informasi Kepada Publik Oleh Direktorat Jenderal Pajak, Volume 17, No Nomor, 2020.

Larensius Arliman S, Koordinasi PT. Pegadaian (Persero) Dengan Direktorat Reserse Narkoba Polda Sumbar Dalam Penimbangan Barang Bukti Penyalahgunaan Narkotika, UIR Law Review, Volume 4, Nomor 2, 2020, https://doi.org/10.25299/uirlrev.2020.vol4(1).3779.

Laurensius Arliman S, Tantangan Pendidikan Kewarganegaraan Pada Revolusi 4.0, Ensiklopedia Sosial Review, Volume 2, Nomor 3, 2020.

Muhammad Afif dan Laurensius Arliman S, Protection Of Children's Rights Of The Islamic And Constitutional Law Perspective Of The Republic Of Indonesia, Proceeding: Internasional Conference On Humanity, Law And Sharia (Ichlash), Volume 1, Nomor 2, 2020.

Otong Rosadi danLaurensius Arliman S, Urgensi Pengaturan Badan Pembinaan Idelogi Pancasila Berdasarkan Undang-Undang Sebagai State Auxiliary Bodies yang Merawat Pancasila dalam Perspektif Hak Asasi Manusia, Prosiding Konferensi Nasional Hak Asasi Manusia, Kebudayaan dan Tujuan Pembangunan Berkelanjutan Indonesia pada Masa Pandemi Covid-19: Tantangan untuk Keilmuan Hukum dan Sosial Volume 1, Universitas Pancasila, Jakarta, 2020. 